\title{
El Partido Peronista argentino: diseños organizativos y prácticas políticas (1947-1955)
}

Oscar Aelo*

Universidad del Mar del Plata, Buenos Aires, Argentina

\section{RESUMO}

O peronismo como força política ou identidade popular tem sido amplamente pesquisado desde as suas origens em 1945 até nossos dias. Menos interesse tem concitado o estudo da organização partidária que os peronistas construíram. Este artigo analisa a configuração do Partido Peronista entre 1947 e 1955, os dilemas e conflitos que os organizadores partidários enfrentaram e as lutas pelo poder no interior do partido entre os diversos grupos dirigentes, que resultaram na constituição de dois modelos de partido diferentes.

Palavras-chave: peronismo; partidos políticos; desenhos organizativos; democracia; verticalismo.

\section{RESUMEN}

El peronismo como fuerza política o identidad popular ha sido profusamente investigado desde sus orígenes en 1945 hasta nuestros días. Menor interés ha concitado el estudio de la organización partidaria que los peronistas construyeron. En este artículo se analiza la configuración del Partido Peronista entre 1947 y 1955, los dilemas y conflictos enfrentados por los organizadores partidarios y las disputas por el poder al interior del partido entre diversos grupos dirigentes, que dieron como resultado el establecimiento de dos diferentes modelos de partido.

Palabras-clave: peronismo; partidos políticos; diseño organizativo; democracia; verticalismo.

\section{ABSTRACT}

Peronism as a political force or popular identity has been extensively investigated from its origins in 1945 to today. Less interest has attracted the study of the party organization that peronists built. This article analyzes the configuration of the Peronist Party between 1947 and 1955, the dilemmas and conflicts faced by party organizers and the struggle for power within the party between different ruling groups, that resulted on the establishment of two different models of political party.

Keywords: peronism; political parties; organizational design; democracy; top-down organization.

DOI - http://dx.doi.org/10.1590/2237-101X017033013

* Professor na Universidad del Mar del Plata. E-mail: oscar.aelo@yahoo.com.ar. 


\section{Introducción}

Desde sus orígenes a mediados de la década del cuarenta del siglo pasado hasta la actualidad, el peronismo ha constituido un permanente objeto de indagación para historiadores y otros cientistas sociales. Una nutrida, por no decir enorme bibliografía ha intentado comprender o explicar diversos aspectos de ese "enigma" de la política argentina. Los estudios dedicados al análisis de la organización partidaria que los peronistas han construido, sin embargo, no destacaron por volumen ni por profundidad. En reiteradas ocasiones, el lugar del análisis ha sido ocupado por comentarios tangenciales, adjetivaciones o preconceptos. Así, el partido de los peronistas ha sido calificado como personalista, autoritario, monolítico; o bien como ficticio, inauténtico o mero apéndice estatal. Llegó a afirmarse, inclusive y asombrosamente, que "nadie podrá escribir la historia del Partido Peronista (...) porque no existió; (...) fueron los suyos lustros burocráticos y administrativos, chatos, sin alma". ${ }^{1}$

En las dos últimas décadas, la historiografía política, tanto desde un enfoque nacional como desde perspectivas provinciales ha venido escribiendo esa historia que ciertamente existió. ${ }^{2}$ En este artículo argumentaré que entre los años 1947 y 1955, el Partido Peronista tuvo dos estructuras distintas, cuyo establecimiento fue resultado de la actividad práctica de los actores partidarios. Las tensiones organizativas que lo recorrieron fueron originadas, en principio, por la honda movilización popular que impulsó/canalizó el peronismo. Pero también, por las luchas entre grupos dirigentes por el control de la organización y el modo de integración del "pueblo" en su interior. De las tres "caras" interrelacionadas que un partido eventualmente puede mostrar (en el llano, en las agencias centrales, en los puestos públicos) este trabajo privilegiará el análisis de las agencias directivas del Partido Peronista; realizará, cuando sea necesario a propósitos explicativos, referencias a los otros rostros del partido.

Antes de entrar en materia, convendría precisar mínimamente ciertos rasgos contextuales:

a) el Partido Peronista nunca fue, ni funcionó como, un partido único. Siempre estuvo inmerso en la competencia con otros partidos, siendo sus adversarios principales la Unión Cívica Radical, el Partido Socialista, el Partido Comunista y el Partido Demócrata;

\footnotetext{
${ }^{1}$ LUNA, Félix. Perón y su tiempo. I. La Argentina era una fiesta 1946-1949. Buenos Aires: Sudamericana, 1984 , p. 60.

${ }^{2}$ El único libro que desde una perspectiva nacional se ocupa del tema es MACKINNON, Moira. Los años formativos del Partido Peronista. Buenos Aires: Siglo XXI-Instituto Torcuato Di Tella, 2002. Tres compilaciones reúnen una parte sustantiva de la ingente investigación provincial: MACOR, Darío; TCACH, César (Eds.). La invención del peronismo en el interior del país. Santa Fe: Universidad Nacional del Litoral, 2003; AELO, Oscar H. (Comp.). Las configuraciones provinciales del peronismo: actores y prácticas políticas, 1945-1955. La Plata: Instituto Cultural de la Provincia de Buenos Aires, 2010; MACOR, Darío; TCACH, César (Eds.). La invención del peronismo en el interior del país II. Santa Fe: Universidad Nacional del Litoral, 2013.

${ }^{3}$ KATZ, Richard; MAIR, Peter. The Ascendancy of the Party in Public Office: Party Organizational Change in Twentieth-century Democracies. In: GUNTHER, Richard; MONTERO, José Ramón; LINZ, Juan J. (Eds.). Political Parties: Old Concepts and New Challenges. Oxford: Oxford University Press, 2002, p. 113-135.
} 
b) el régimen político argentino, antes, durante y después del peronismo, siempre sostuvo un sistema representativo, republicano y federal (excepto bajo regímenes dictatoriales). Del voto del pueblo — bajo la modalidad de secreto y obligatorio — dependían las autoridades nacionales (Presidente, Congreso nacional), provinciales (gobernador, legislatura) y municipales (intendente y concejales). En el período que trata este trabajo, la estructura federal estaba compuesta por catorce provincias y la ciudad de Buenos Aires (Capital Federal);

c) ese régimen político encontraba su arquitectura en la Constitución Nacional de 1853, que fue reformada en 1949. En esta reforma, lo que podría considerarse significativo para el régimen político fue la elección directa de los senadores (antes, elegidos por las legislaturas provinciales) y del presidente de la nación (antes, vía un Colegio Electoral). Sin duda, la piedra del escándalo — tanto en la época, cuanto en evaluaciones posteriores- fue la posibilidad de reelección presidencial indefinida;

d) hasta 1950, el calendario electoral argentino fue abigarrado y diverso. Se desarrollaron elecciones prácticamente todos los años desde 1946, siendo en algunos casos de orden provincial o municipal y en otros nacional. A partir de 1951 y hasta 1955, las elecciones de todos los niveles fueron unificadas, y todos los niveles de cargos se disputaron en las mismas fechas: noviembre de 1951 y abril de 1954;

e) a partir de 1951, hubo modificaciones en las leyes electorales, tanto nacional cuanto provinciales. El aspecto más criticado fue el sistema elegido para transformar votos en bancas en el caso de los diputados nacionales, al pasarse de un sistema de "lista incompleta" a uno "uninominal por circunscripciones". Por el contrario, en las provincias se adoptó un sistema de mayoría y minorías. En todos los casos, se modificó el lapso por el cual los legisladores eran elegidos (se pasó de cuatro a seis años);

f) en lo sustantivo, en la década se amplió notablemente el cuerpo electoral, a través de la sanción de leyes que establecieron el voto femenino y la provincialización de territorios nacionales.

En lo que sigue, los dos diseños que, en la década, tuvo el Partido Peronista — uno entre 1947 y 1951; el siguiente entre 1951 y 1955 — serán analizados sucesiva y comparativamente, tejiéndose finalmente algunas conjeturas explicativas del pasaje de uno a otro.

\section{El Partido-movimiento (1947-1951)}

"Con el nombre de "Partido Peronista" queda definitivamente organizado el Movimiento de la Revolución Nacional...”. Con estas palabras comenzaba la Carta Orgánica sancionada por los congresales de la organización en diciembre de 1947. ¿Qué fuerzas habían compuesto ese "movimiento"? ¿Qué tipo de organización se pretendía haber alcanzado "definitivamente"? 


\section{El peronismo antes del Partido Peronista}

En junio de 1943 los militares intervenían en la política argentina derrocando un régimen conservador, supuestamente "democrático", basado en la alteración fraudulenta de resultados electorales. La "Revolución de Junio", como se denominó, contó inicialmente con la simpatía activa de los partidos opositores al dominio conservador (radicales y socialistas, principalmente); simpatía que a corto plazo se transformó en rudo antagonismo, en particular ante la acción desplegada por quien poco a poco se transformó en el "hombre fuerte” del gobierno militar, Juan Perón. A lo largo de 1945, la fracción de la elite políticomilitar que promovía una salida institucional a través de la candidatura presidencial de Perón politizó la gestión estatal a través de las Intervenciones Federales en las provincias y la actividad de la Secretaría de Trabajo y Previsión. En el primer caso, las políticas o prácticas discursivas que enfatizaban en el componente "justicia social" se conjugaba con la amplísima colaboración-integración de dirigentes de segunda línea del Partido Radical. En el segundo caso, los funcionarios de la Secretaría de Trabajo - tanto en el centro como a través de sus delegaciones regionales - activaban desgajando y atrayendo hacia la nueva alternativa política diversas organizaciones, militantes y cuadros sindicales. La crisis de la dominación tradicional, agudizada por la propia gestión estatal "preperonista", acrecentaba las oportunidades de acción de diversos grupos populares, cuyo estado de movilización se mostraría nítidamente en las manifestaciones del 17 de octubre de 1945, en Buenos Aires y otros lugares del país, que fracturaron ostensible y — aunque no lo sabían- permanentemente el escenario político argentino. ${ }^{4}$

Las fuerzas articuladoras de la coalición peronista fueron el Partido Laborista y la Unión Cívica Radical (Junta Renovadora). El primero era conformado por reconocidos líderes sindicales, reacios a toda forma de la "vieja política", como la plataforma de concreción de los ideales innovadores y revolucionarios de la clase obrera. El segundo era organizado por dirigentes desprendidos de la Unión Cívica Radical — parte de los cuales eran funcionarios del Estado en diversos niveles - quienes se presentaban como portadores de la tradición "nacional y popular" de aquel partido, y aportaban cierta experiencia política y probables apoyaturas electorales rurales y urbanas en el interior argentino. Durante la campańa electoral, estas fuerzas —y otras menores, de raigambre provincial— expusieron públicamente más de una vez las que consideraban hondas divergencias.

\footnotetext{
${ }^{4}$ En contraposición al preconcepto según el cual en las provincias "tradicionales" no habría movilización popular o participación política, pueden verse KINDGARD, Adriana. Procesos sociopolíticos nacionales y conflictividad regional. Una mirada alternativa a las formas de acción colectiva en Jujuy en la transición al peronismo. Entrepasados, Buenos Aires, n. 22, p. 67-87, 2002; o MARTÍNEZ, Ana Teresa. La prehistoria del peronismo en Santiago del Estero. Laborismo, radicalismo y política criolla en las elecciones de 1946. Quinto Sol, La Pampa, n. 12, p. 73-92, 2008. Sobre la movilización obrera, JAMES, Daniel. El 17 y 18 de octubre de 1945: el peronismo, la protesta de masas y la clase obrera argentina. Desarrollo Económico, Buenos Aires, n. 107, p. 445-461, 1987.
} 
Los resultados de la elección del 24 de febrero de 1946 mostraron que la conjunción de fuerzas peronistas había conseguido colocar a su candidato en la Presidencia del país; obtenía también 13 de las 14 gobernaciones provinciales; lograba una amplia mayoría en la Cámara de Diputados de la Nación; y mayorías no siempre amplias en casi todas las Legislaturas de provincia. Las tensiones entre laboristas y renovadores recrudecieron en las luchas por ocupar espacios de poder: en la elección de senadores nacionales; en los gabinetes de los ejecutivos provinciales; en las autoridades de los cuerpos legislativos nacionales y provinciales. Los integrantes de la cúpula más cercana a Perón instaron reiteradamente a la unidad para facilitar la gestión gubernamental..$^{5}$ Pero el fracaso de estos intentos, que parecía augurar la disolución de la coalición, impulsó a Perón a intervenir directamente. En una proclama leída por radio el 23 de mayo de 1946, el presidente electo, asumiendo el título de "Jefe Supremo del Movimiento", ordenaba:

Caducan en toda la República las autoridades partidarias actuales de todas las fuerzas que pertenecen al Movimiento Peronista; (...) Como Jefe, encargo en la fecha a los camaradas legisladores (...) la organización de todas las fuerzas peronistas como Partido Único de la Revolución Nacional. ${ }^{6}$

La "orden” de Perón forzaba la unificación de las fuerzas que le eran adictas; sin embargo, acaso previsiblemente, no resolvía sus discordias sino que las trasladaba al interior del nuevo Partido Único de la Revolución. La búsqueda de un proyecto organizativo que contuviera las disímiles fuerzas aliadas/enemigas, insumió largos debates y ninguna resolución firme; la composición de las Juntas Provinciales incentivaba las disputas; la posibilidad de rearticulación de las fuerzas originarias - a veces concretada - era una amenaza latente. En ese marco, una reunión nacional de dirigentes realizada a finales de 1946 resolvió, buscando seguramente reaseguros simbólicos de una unidad frágil, renombrar al partido como Peronista. Al mismo tiempo, cancelaba el órgano directivo nacional hasta entonces actuante — denominado Junta Ejecutiva—y lo reemplazaba por otro denominado Consejo Superior. ${ }^{7}$

\footnotetext{
5 "Concitamos al pueblo a propiciar la unidad radical-laborista, en una conjunción partidaria, que con una sola doctrina se dedique, para bien de la Patria, a estructurar el partido de gobierno (...)”. La Nación (Buenos Aires), 8 abril 1946.

${ }^{6}$ La proclama íntegra de Perón puede verse en CURSACK, Roberto Enrique. Ideario social y político del Partido Único de la Revolución Nacional. Su organización en la Provincia de Buenos Aires. Buenos Aires: 1947, p. 13-17.

${ }^{7}$ Los dilemas sintéticamente expuestos aquí son ampliamente tratados en MACKINNON, Moira. Los años formativos del Partido Peronista, op. cit.
} 


\section{La Carta Orgánica de 1947}

El Partido Peronista aparecía públicamente el 15 de enero de 1947. Al poco tiempo, se encontraba envuelto en las disputas que surcaban todos los peronismos provinciales, en particular en aquellos donde el calendario electoral fijaba comicios para los primeros meses del año. Un ejemplo característico se dio en Mendoza, donde a los desacuerdos en torno a la configuración de la Junta de Organización partidaria se sumó la necesidad de seleccionar candidatos provinciales y municipales. El instrumento utilizado por los peronistas mendocinos consistió en la realización de elecciones internas. Aunque el método no canceló las fricciones entre los antagonistas locales, prefiguró una de las formas que el peronismo tenía a mano para resolver sus disidencias. ${ }^{8}$ Así parecieron entenderlo las autoridades nacionales del partido, al pautar una elección interna con el objeto de seleccionar delegados para el Congreso Nacional del Partido. La compulsa se realizó el 21 de setiembre de 1947, simultáneamente en todas las provincias del país. ${ }^{9}$ Aunque no faltaron críticas a algunas Juntas Partidarias de distrito por "favoritismo" u otras anomalías, el desarrollo del proceso electoral ofreció una muestra de las potencialidades pluralistas y participativas que el peronismo albergaba. Así, los observadores del proceso en la provincia de Buenos Aires indicaban:

El comentario que unánimemente ha podido recogerse (...) es que pocas veces se ha registrado en la Provincia y, sin duda, cabe hacer extensivo el concepto al resto del país, un clima de entusiasmo tan vivo y fervoroso en comicios que se relacionan exclusivamente con el funcionamiento de una agrupación política. ${ }^{10}$

Los delegados electos se reunieron los días 1 y 2 de diciembre de 1947 en la ciudad de Buenos Aires en el primer Congreso Nacional del Partido Peronista que asumía, de este modo, características de constituyente. Entre las resoluciones más significativas del congreso estuvo la sanción del estatuto partidario. ${ }^{11}$ El documento conjugaba las disímiles concepciones partidarias de que eran portadores los dirigentes peronistas. La Carta establecía cuatro organismos de alcance nacional: el Congreso, formado por delegados electos por el voto directo de los afiliados; el Consejo Superior Ejecutivo, compuesto por miembros designados por las autoridades provinciales y territorianas; el Tribunal de Disciplina (designado por el Consejo Superior); y el Buró de Difusión (designado por el Congreso). Un segundo orden

\footnotetext{
${ }^{8}$ Ver GARZÓN ROGÉ, Mariana. Prácticas políticas en la construcción del Partido Peronista. Mendoza, 1946-1948. Estudios Sociales, Santa Fe, año XXII, n. 42, p. 91-118, 2012.

${ }^{9}$ Democracia, 22 setiembre 1947. No se realizaron por problemas políticos locales en San Juan y Corrientes (en esta provincia la elección interna tuvo lugar el 9 de noviembre).

${ }^{10}$ El Argentino (La Plata), 21 setiembre 1947.

${ }^{11}$ Carta Orgánica Nacional [1947]. In: Doctrina Peronista, Presidencia de la Nación, Subsecretaría de Informaciones y Prensa, 1951, p. XXVII-XLII.
} 
de autoridades partidarias eran las provinciales: un Congreso o Asamblea elegida por voto directo; y un Consejo Partidario, electo por el Congreso provincial. Por debajo de ellos, la Carta establecía que en cada municipio se constituiría un Consejo Directivo local, electo por voto directo. Finalmente, la normativa regía la constitución de los organismos de base, denominados "unidades básicas". Estas podían ser de dos tipos, gremiales u ordinarias, y sus autoridades se elegían por voto directo.

El articulado del estatuto partidario peronista recogía en parte concepciones y prácticas más o menos "tradicionales" de las que fueron portadoras sus fuerzas originarias; expresaba en parte anhelos e ilusiones; en parte, también, intentaba brindar un cauce orgánico para la actividad partidaria de militantes y dirigentes. Pero ese "cauce" era multidimensional, abierto a disímiles interpretaciones, en torno a las cuales podría desarrollarse la acción de sus integrantes.

\section{El fortalecimiento de la agencia central}

El esqueleto organizativo que los peronistas establecían en el congreso fundacional de su partido debía ser actualizado en la práctica concreta. Del conjunto de autoridades partidarias establecidas en la Carta Orgánica, pocas se encontraban en funciones. Una resolución del Congreso convalidó todo lo actuado por el Consejo Superior y prorrogó los mandatos de sus integrantes — hasta que el partido se normalizara. Por debajo del máximo organismo, los Consejos Directivos locales estaban en vigencia en la provincia de Buenos Aires - no así en otras provincias - , y muy probablemente todas las autoridades de unidades básicas existentes. Cabe remarcar, adicionalmente, que durante octubre de 1947 el Consejo Superior, probablemente ante la efervescencia aumentada como consecuencia de la elección interna, resolvió designar interventores partidarios en cada distrito provincial con el propósito de dirigir la reorganización partidaria. Estos interventores fueron, en todos los casos, legisladores nacionales (no electos en la provincia donde actuaban como interventores).

Una vez sancionado el estatuto, durante 1948 el Partido Peronista debió enfrentar dos elecciones generales, en marzo y en diciembre. Los responsables de la gestión partidaria ensayaron dos mecanismos distintos para designar candidatos. En el marco del Congreso Constituyente del partido, los delegados sancionaron una cláusula provisoria por la cual las convenciones partidarias provinciales (formadas por los mismos delegados al congreso partidario nacional) se encargarían de confeccionar las listas de candidatos para las elecciones de marzo. ${ }^{12}$ La disposición efectivamente se llevó a la práctica, aunque hubo presiones desde el Consejo Superior sobre algunas asambleas provinciales (a través de los interventores) para componer o modificar las nóminas. En las elecciones de diciembre de 1948, convocadas

${ }^{12}$ Véase Carta Orgánica Nacional [1947], Art. 51ํㅜ, p. XLII. 
para escoger convencionales constituyentes, el criterio fue otro. El Consejo Superior, argumentando en torno al "estado de asamblea en que se encuentra el partido, esto es, la carencia de autoridades del mismo, y la imposibilidad de dar a cada provincia sus respectivos comités o convenciones", ${ }^{13}$ concentró en sus manos la confección de las listas. La experiencia sancionaba aquí un mecanismo inverso al anterior: de la descentralización se pasaba a la centralización. Ello no significa necesariamente que el Consejo Superior resolviese sobre candidaturas sin tener en cuenta las opiniones vertidas por diversos medios — a veces, en campañas abiertas - de los dirigentes locales. En las elecciones subsiguientes, realizadas durante 1949 y donde se elegían, en diversas provincias, gobernadores y legisladores, la actuación del Consejo Superior fue —en general — similar: mediando/imponiendo alguna de las candidaturas que las impenitentes facciones peronistas en cada provincia levantaban. De todos modos, y hasta las elecciones de 1950 inclusive — con una única y significativa excepción, a la que haremos referencia más abajo- el Consejo Superior partidario fue concentrando la tarea de decidir sobre candidaturas a elecciones generales.

Otros procesos internos del partido también dan cuenta del gradual fortalecimiento del organismo directivo central. Uno es el reforzamiento de la autoridad de los interventores; otro, el intento por poner "orden" en el desorden peronista de base. En unas "instrucciones generales” para los Interventores del partido en las provincias, territorios y la Capital Federal, el Consejo Superior resolvía:

\section{Interventores:}

1. Representan la autoridad máxima del Partido en el distrito de su designación y reemplazan a todos los organismos superiores estatuidos.

2. Son responsables de la inculcación de la doctrina peronista y de la organización definitiva del Partido en el distrito a su cargo. ${ }^{14}$

Se encargaba al Interventor organizar el fichero de afiliados, abrir/reabrir la afiliación en determinado momento, organizar las tareas de difusión doctrinaria, designar "delegados" en los departamentos y asignarles tareas, etc. En síntesis, aun cuando la resolución referida imagina al Interventor como una figura "transicional" (hasta la "organización definitiva") la suma de poderes que se le atribuyen —amén de la no indicación de período alguno en que debe efectuar sus funciones - alientan la posibilidad de una estabilización de la figura del Interventor (más allá de la persona que ocupe tal cargo) y, por su intermedio, el creciente poder de decisión del Consejo Superior.

La militancia popular, tal como emergida hacia 1945 y posteriormente, tendió a agruparse en un conjunto de organismos diversos: comités, centros cívicos, bibliotecas populares,

\footnotetext{
${ }^{13}$ La Capital (Mar del Plata), 23 octubre 1948.

${ }^{14}$ Consejo Superior del Partido Peronista, Libro de Resoluciones, Fo 86, 10 junio 1949. 
ateneos, etc. Es interesante destacar que estos agrupamientos transitan sin solución de continuidad desde el 17 de octubre, o antes, hasta al menos 1949 o 1950. Adicionalmente, parece que existían diversos centros que utilizaban la denominación "peronista" sin formar parte orgánica del partido. Así, el Consejo Superior intentaría "poner orden" disponiendo que, para formar parte del partido, el centro debía denominarse "unidad básica”, y que sólo sería tal una vez "autorizada" por las respectivas Intervenciones distritales.

Así lo indicó el Interventor partidario en Santa Fe:

En su resolución № 3 prohibió el uso de los términos "peronista" o "peronismo" a todo organismo que no se halle autorizado (...) En adelante todas las organizaciones existentes o que se constituyan, para poder actuar, tendrán que llamarse "Unidades Básicas" y pedir su reconocimiento como tales a la Intervención, de acuerdo a lo que dispone la Carta Orgánica del Partido. ${ }^{15}$

Asimismo, el Consejo Superior fortalecido podía "disciplinar" no sólo díscolos militantes o dirigentes de base. Legisladores y aún gobernadores fueron censurados y/o expulsados por un organismo que se atribuía inclusive la definición del peronismo: "Que no es posible que al amparo de la Bandera de Perón hayan quienes crean que son peronistas con solo invocar su nombre, mientras trabajan por destruir la obra común de los verdaderos peronistas (...).”16

\section{Politicos y "sindicalistas": el final del peronismo (partidario) obrero}

La gradual concentración de poder por la agencia central del partido corría en paralelo con el creciente desdibujamiento del perfil obrero de la organización partidaria. Una venerable interpretación sostiene que la finalidad de la creación del Partido Único — luego peronista - era limitar o impedir la acción "autónoma" de la clase obrera en el sistema político. ${ }^{17}$ Es posible que esa fuera la "idea" de Perón y sus allegados. Pero además de esta cuestión existía otro problema, vinculado a las fuentes de poder al interior del partido que podían, eventualmente, blandir los actores partidarios. Antes inclusive que Perón ordenara la unificación, el gobernador de Salta lo había formulado claramente:

(...) siendo incompatibles las actividades políticas con las gremiales, los que ejerzan la dirección, o formen parte o integren las comisiones directivas de las asociaciones obreras, no pueden

\footnotetext{
${ }^{15}$ El Orden (Santa Fe), 23 setiembre 1949.

${ }^{16}$ Consejo Superior del Partido Peronista, Libro de Resoluciones, Fo 135, 23/12/1949. Fueron expulsados del partido el gobernador en ejercicio y el senador nacional electo de Catamarca; también seis legisladores provinciales de San Juan.

${ }^{17}$ Ver, entre otros, TORRE, Juan Carlos. La vieja guardia sindical y Perón. Buenos Aires: Sudamericana, 1990.
} 
aspirar a ser, al mismo tiempo, dirigentes políticos. Deben, pues, optar por ser dirigentes gremiales o dirigentes políticos. ${ }^{18}$

En la organización primigenia del Partido Laborista, tal distinción estaba de hecho cancelada: al privilegiar la integración directa de los sindicatos en el partido, los dirigentes eran, o podían ser, indistintamente "sindicalistas" y "políticos". En el Partido Peronista, los laboristas pretendieron incidir retomando aquella pauta de su estructura previa. No lo consiguieron. El débil eco de la perspectiva laborista en la Carta Orgánica puede oírse apenas en los artículos referidos a las unidades básicas "gremiales". Hacia 1949, al unísono con la concentración de la autoridad decisoria y la definición del "verdadero" peronismo, el Consejo Superior establecía criterios para las unidades básicas que suprimían de hecho aquella modalidad:

Es también importante esclarecer que este organismo está compuesto por hombres que desarrollan actividades personales de todo tipo. Es decir que debe procurarse que en los mismos tengan participación toda clase de ciudadanos cualquiera sea su actividad profesional. No debe olvidarse que no somos un partido clasicista, sino un partido revolucionario de unidad nacional. ${ }^{19}$

Asimismo, y aun cuando los datos son muy incompletos, se puede plantear como hipótesis que las candidaturas a cargos públicos por el Partido fueron siendo mayoritariamente ocupadas por personas que no respondían a organizaciones sindicales, sino que desarrollaban su actividad prioritaria o exclusivamente en las filas partidarias. Este fue el caso de la provincia de Buenos Aires, en las elecciones de renovación parlamentaria de 1948 y 1950. También en Tucumán, donde un agudo conflicto gremial azucarero desarrollado durante 1949 acabó en la derrota del sindicato (FOTIA). Pero como los líderes de ese sindicato habían también "hegemonizado" el partido en esa provincia, su derrota sindical se transformó en derrota partidaria — seguida por una serie de expulsiones de dirigentes - lo que posibilitó un proceso de "profesionalización" de los grupos dirigentes partidarios, plenamente sostenidos por la cúpula nacional del partido. ${ }^{20}$

${ }^{18}$ Cámara de Senadores, Diario de Sesiones, 14 mayo 1946, Salta. Citado en DEL VALLE MICHEL, Azucena. Conflictos en los primeros años del peronismo salteño (1946-1949). In: AELO, Oscar H. (Comp.). Las configuraciones provinciales del peronismo: actores y prácticas políticas, 1945-1955, op. cit., p. 69.

${ }^{19}$ Consejo Superior del Partido Peronista, Libro de Resoluciones, Fo 93, 10 junio 1949. (Es evidente que el sentido de "clasicista" es "clasista").

${ }^{20}$ Ver GUTIÉRREZ, Florencia; RUBINSTEIN, Gustavo. De la hegemonía sindical al peronismo "político”. La reestructuración del partido peronista tucumano, 1949-1952. Primer Congreso de Estudios sobre el Peronismo: la primera década, Red de Estudios sobre el Peronismo/Universidad Nacional de Mar del Plata, 2008. 


\section{Facciones y poder partidario}

Unificado partidariamente el peronismo, las corrientes originarias (laboristas, renovadores, nacionalistas) fueron subsumidas en el amplio arco de facciones que emergieron a lo largo y ancho del país. Las elecciones internas de 1947 precipitaron a la luz pública un crudo faccionalismo, que no reservaba epítetos para señalar a sus adversarios internos. Esos grupos más o menos organizados raramente se constituían en derredor de propuestas partidarias específicas. El peronismo mostraba un "aire de familia" con los partidos anteriores —en particular, con la Unión Cívica Radical - en el sentido del "personalismo” que primaba en la constitución de las facciones. ${ }^{21}$ El predominio de una u otra facción en las provincias a finales de 1947 no quedó garantizado por la victoria en la elección interna. La tentativa de "unificar" esas fracciones con poco ánimo de unidad a través de la designación de Interventores realizada por el Consejo Superior sólo en parte apaciguó los ánimos. En parte, y dependiendo del distrito provincial, los recalentó. En las elecciones de marzo de 1948, diversos grupos disconformes con el dominio partidario de algún otro grupo precipitaron rupturas y la presentación a elecciones bajo otra etiqueta partidaria: en Jujuy, el Partido Concentración Obrera 4 de Junio; en Salta, el Frente Revolucionario 4 de Junio; en Tucumán, el Frente Obrero Peronista Revolucionario; en Santa Fe, en lo que constituyó el mayor alzamiento a la autoridad de la agencia central del peronismo, el Partido Obrero de la Revolución (que contaba en sus filas al gobernador en ejercicio, y otros funcionarios y legisladores). El faccionalismo se manifestaba también en la propia gestión gubernamental, reiterando -otra vez - pautas tradicionales de la política argentina: gobernadores enfrentados con legislaturas (y viceversa), solicitudes "desde abajo" de Intervención Federal. Cuando esta última "solución" se hacía efectiva, usualmente no se apagaban las disputas facciosas sino que volvían a recomenzar.

En algunos casos, ese faccionalismo pudo dar lugar a la emergencia de un grupo dirigente provincial más sólido, que eventualmente consiguió hegemonizar al peronismo, al menos durante un período. Así, el "zavalismo" de San Luis, sin opositores internos de peso; el "tanquismo" de Jujuy, reiteradamente vencedor sobre sus opositores; el sindicalismo azucarero tucumano (al menos, hasta 1949); el "mercantismo" bonaerense. Y este último es un caso particular, en tanto al contrario de otras facciones de alcance exclusivamente provincial, el predominio sobre Buenos Aires, la principal provincia argentina en términos de riqueza y población, fue la base de operaciones para una "apuesta" de control partidario de alcance nacional. Aunando una sólida gestión gubernamental, la conducción de un homogéneo equipo dirigente político-partidario y privilegiados lazos con la pareja presidencial, el Gobernador Domingo Mercante se transformó en un dirigente nacional del peronismo.

\footnotetext{
${ }^{21}$ Ver PERSELLO, Ana Virginia. El Partido Radical: gobierno y oposición, 1916-1943. Buenos Aires: Siglo XXI, 2004.
} 
A comienzos de 1949, los mercantistas escalaban a los puestos de decisión en el Consejo Superior del Partido Peronista. ${ }^{22}$ Las tareas emprendidas desde ese organismo muestran un triple orden de propósitos: aumentar el poder del Consejo, dinamizar la actividad partidaria, mantener y reforzar los mecanismos representativos.

El fortalecimiento de la agencia central la mostramos más arriba. La dinamización organizativa se enfatizó con la convocatoria a la "Reunión Nacional Partidaria" en julio de $1949 .{ }^{23}$ En la magna reunión, de la que participaron alrededor de 4500 delegados y delegadas de todas las provincias y territorios del país ${ }^{24}$, sobrevinieron - pese a que fue ideada como "expositiva", no "deliberativa" — agudas discusiones en torno a los lineamientos de organización del partido; al punto que el titular del Consejo Superior, Alberto Teisaire un dirigente que expresaba claramente una tendencia interna poco propensa a la democracia partidaria— se vio obligado a expresar:

(...) hablar de organización del partido es hablar de reclutamiento, ordenamiento y gobierno del mismo; el ordenamiento y el reclutamiento se resuelven con una afiliación intachable que produzca un padrón partidario absolutamente correcto, con el que se irá a una elección interna de indiscutible fuerza, dirigida y controlada en cada distrito por el consejo superior ejecutivo, y el gobierno del partido estará encuadrado en la carta orgánica, con sus unidades orgánicas bajo sus respectivos dirigentes. ${ }^{25}$

De este modo, la dinamización del partido se correspondía con la pretensión de mantener y reforzar los mecanismos representativos, en este caso referidos a la organización interna. Hacia finales de 1949, los mercantistas redoblaron la apuesta, al convertir el escenario bonaerense en el laboratorio de experimentación del organigrama partidario, a través de elecciones internas que renovaban autoridades partidarias comunales, designaban delegados al Congreso provincial el cual, a su vez, seleccionaba los candidatos a cargos públicos y establecía el Consejo Directivo provincial: procedimientos y organismos que se ajustaban a los fijados en la Carta Orgánica. En el Congreso provincial del partido, uno de los integrantes de la facción mercantista, a la sazón Secretario de Organización del Consejo Superior, afirmó:

\footnotetext{
${ }^{22}$ Dice Mackinnon: "La pulseada interna respecto de la distribución de poder dentro del partido, entre los sublíderes, parece haberla ganado Mercante (...)"; en MACKINNON, Moira. Los años formativos del Partido Peronista, op. cit., p. 158.

${ }^{23}$ Consejo Superior del Partido Peronista, Libro de Resoluciones, Fo 98, 11 junio 1949.

${ }^{24}$ Esta asamblea fue el marco de fundación del Partido Peronista Femenino. Sobre esta singular organización puede verse BARRY, Carolina. Evita capitana. El Partido Peronista Femenino, 1949-1955. Caseros: Universidad Nacional de Tres de Febrero, 2009.

${ }^{25}$ La Nación (Buenos Aires), 27 julio 1949.
} 
Evidentemente, este hecho es auspicioso, (...) porque lógicamente es el paso inicial en toda la República, para que todos los distritos electorales elijan sus propias autoridades por el voto directo de sus afiliados, y así paulatinamente, esperemos los peronistas, que se irá, paso a paso, perfeccionando la organización partidaria $(. . .)^{26}$

Desde febrero a noviembre de 1950, "el paso inicial" fue sucedido por otros en San Luis, San Juan, Jujuy, Córdoba, Tucumán, Santa Fe, Salta. Con porcentajes de participación generalmente alta, los afiliados peronistas eligieron Consejos Departamentales y, según, el distrito, autoridades de unidades básicas. Estas elecciones internas, aunque ciertamente legitimaban sus cuerpos dirigentes al menos al nivel de base, en ningún caso establecieron los organismos directivos de escala provincial (Congreso, Consejo Directivo) estatuidos. Por diversas razones, la apuesta del mercantismo se estancó hacia finales de 1950 y, en un desenlace para nada previsible, se revirtió desde 1951.

\section{El “partido-rama” (1951-1955)}

"El Partido Peronista es una de las partes que componen el Movimiento Peronista, siendo las otras el Partido Peronista Femenino y la Confederación General del Trabajo". En documentos de 1952, el Consejo Superior establecía en esos términos el "lugar" del partido en el movimiento y, al mismo tiempo, definía un nuevo formato partidario. ¿Cómo se procesó este rediseño organizativo? ¿Qué efectos tuvo sobre el partido de los peronistas?

\section{Crisis cupular y reconfiguración partidaria}

A lo largo de 1951, la antinomia que dividía al país entre peronistas y anti-peronistas se intensificó. Pero al mismo tiempo se operaba un rudo antagonismo al interior del peronismo que, en lo relativo al Partido Peronista, se manifestó en una dura disputa por el control de sus órganos directivos que se saldó con el desplazamiento de los mercantistas. Los integrantes de esa facción en el Consejo Superior renunciaron o fueron expulsados. El Consejo Provincial del partido en la provincia de Buenos Aires fue intervenido; sin solución de continuidad la misma suerte corrieron los Consejos Locales. La caída de los mercantistas corría parejas con el fortalecimiento de las facciones "evitista” y "oficialista" en el Consejo Superior. ${ }^{27} \mathrm{El}$ desplazamiento de la facción mercantista era correlativo a un gradual endurecimiento de la

\footnotetext{
${ }^{26}$ El Día (La Plata), 31 diciembre 1949.

${ }^{27}$ Desde 1949 y hasta esta crisis, los espacios de poder al interior del Consejo Superior se distribuían entre esas tres facciones. Véase MACKINNON, Moira. Los años formativos del Partido Peronista, op. cit.
} 
gestión partidaria. En junio de 1951, el Consejo Superior comunicaba que la vida partidaria sería regida por la Carta Orgánica Nacional, porque "todos y cada uno de los distritos deben ajustar la orientación y procedimientos generales de toda actividad a una sola dirección”. ${ }^{28}$

La concentración de atribuciones en manos del Consejo Superior se acentuó en el proceso de confección de las listas de candidatos para las elecciones generales. En unos pocos casos el Consejo se avino a mediar ante la imposibilidad de contener las disputas facciosas; en la mayoría, impuso su lista de candidatos. ${ }^{29}$ El criterio general parece haber sido el de sustentar una amplia renovación del personal político. Con todo, hubo notorios altibajos en cada provincia dentro de esta tendencia general. Un estamento de cargos (senadores nacionales) parece haberse manejado con otro criterio: "premiar" gobernadores fieles (10 gobernadores que terminaron en 1952 fueron candidatos al Senado nacional). ${ }^{30}$ Si la concentración en el Consejo Superior de la lista de candidatos pretendía subordinar las siemprevivas facciones peronistas, la reacción de ese organismo ante críticas más o menos abiertas indica su escaso éxito:

Frente a los candidatos elegidos, algunos malos peronistas esgrimen los argumentos más deleznables, a fin de desprestigiarlos en el estrecho sector de sus bastardos intereses (...) Frente a cada candidato no cabe, en la conducta de un peronista de verdad, otra cosa que apoyarlo ahora y votarlo el 11 de noviembre. ${ }^{31}$

La verticalidad que suponía el acatamiento a las directivas de la "sola dirección" no estaba en sintonía con el articulado de la Carta Orgánica. En pocos meses, ésta caducaba de hecho y entraba en vigencia un nuevo esquema.

\section{Nuevas reglas formales}

Al menos desde julio de $1952^{32}$, el Consejo Superior fue preparando y difundiendo primero en forma reservada a los interventores, y pública luego - una serie de documentos que establecían por un lado el diseño organizativo del Movimiento Peronista, y por otro

\footnotetext{
${ }^{28}$ El Día (La Plata), 15 junio 1951.

${ }^{29}$ Véase, para la primera posibilidad, MICHEL, Azucena del Valle; SULCA, Arnaldo; ESPINOSA, Silvia. El Consejo Superior del Partido Peronista y las elecciones generales del año 1951 en la provincia de Salta. Revista Escuela de Historia, Salta, año 5, v. 1, n. 5, p. 189-217, 2006.

${ }^{30}$ Se trató de los gobernadores de Córdoba, Corrientes, Entre Ríos, Jujuy, Mendoza, Salta, San Juan, San Luis, Santiago del Estero y Tucumán.

${ }^{31}$ Mundo Peronista, año I, n. 8, 1 noviembre 1951, p. 36.

${ }^{32}$ Un interventor partidario afirmó: "este contacto con los dirigentes (...) respondía a la necesidad de imponerlos acerca de la nueva estructura del Partido Peronista, siguiendo las directivas del Consejo Superior”. El Litoral (Santa Fe), 17 julio 1952.
} 
modificaban el formato partidario. ${ }^{33}$ En relación al "Movimiento", indicaba las autoridades encargadas de coordinar sus "partes": a) Una Dirección ejercida por el Jefe Supremo del Peronismo, Gral. Perón. b) Un Comando Estratégico, formado por el Consejo Superior del Partido Femenino, el Consejo Superior del Partido Peronista y la Mesa Directiva de la Confederación General del Trabajo. c) Comandos Tácticos (provinciales) formados por un representante de cada una de las "partes" y por el gobernador. d) Subcomandos Tácticos (municipales) formados también por un representante de cada organismo peronista y por el intendente. Es interesante resaltar el virtual borramiento de los límites entre Estado y movimiento político, al indicar que gobernadores e intendentes son integrantes directos de los comandos o subcomandos. ${ }^{34}$

En lo que concierne al Partido, su definición como una de las partes del Movimiento conllevó una visible alteración de su organización interna (la cual, nuevamente, se presumía como "definitiva"). ${ }^{35}$ El Consejo Superior disponía que el gobierno del Partido estaría a cargo de una serie de autoridades "en orden jerárquico decreciente": a) Jefe Supremo; b) Consejo Superior; c) Consejos Provinciales; d) Consejos municipales; e) Consejos de Unidades Básicas. Los tres últimos tendrían una organización horizontal, formada por secretarios de igual jerarquía. Al mismo tiempo, aumentaba la capacidad decisoria de la agencia ejecutiva central, la cual, además, no estaba compuesta por secretarios de "igual jerarquía”. El Consejo Superior tenía entre otras funciones la de designar candidatos a cargos públicos nacionales y también — sino las delegaba a los consejos provinciales — las candidaturas públicas de orden provincial y municipal. Aunque en este formato se prescindía de órganos deliberativos congresos, en diversos niveles-, los criterios representativos no eran olvidados, en tanto se establecía que los Consejos de Unidades Básicas serían electos por el voto directo y secreto de los afiliados. Cabe destacar que sólo perduraban unidades básicas ordinarias, eliminándose las gremiales.

Los Consejos partidarios provincial, municipal y de unidades básicas eran "en sí, comandos y subcomandos tácticos sin comandantes". La finalidad específica de este tipo de organización era "eliminar" al caudillo político. En el discurso peronista, este término adquiría connotaciones sumamente negativas, vinculadas al personalismo político. El formato de partido que se diseñaba evitaba, por lo menos en el papel, esta potencial amenaza. Por otra parte, la reiteración de expresiones como comandos o subcomandos tanto para el partido como para el movimiento incorporaba un elemento de confusión, producto del hermetismo

${ }^{33}$ Partido Peronista. Directivas Básicas del Consejo Superior. Buenos Aires, 1952 (el documento está fechado 16 diciembre 1952). Simultáneamente publicó una serie de "Directivas complementarias" referidas a distintos aspectos de la organización del partido.

${ }^{34} \mathrm{Al}$ redactar este documento, el Consejo Superior parece no haber tomado en cuenta la posibilidad de perder elecciones, en provincias o municipios. Esto es curioso: en la provincia de Buenos Aires, por ejemplo, ocho municipios eran gobernados por la oposición radical

35 "El Partido Peronista (...) entra en la etapa de su organización definitiva (...)”, Directivas Básicas del Consejo Superior, op. cit., p. 3. 
con el cual este doble organigrama se elaboró. Tal vez para aclarárselo a sí mismo, el Consejo Superior afirmaba: "No debe confundirse lo que son Comando Estratégico y Táctico del Movimiento Peronista (...) con lo que son Comandos Estratégicos y Tácticos del Partido Peronista". ${ }^{36}$

Las disposiciones contenidas en las Directivas de 1952 fueron la base de una nueva Carta Orgánica, sancionada por el Consejo Superior a comienzos de 1954, que sólo innovaba creando una Junta Consultiva Nacional, formada por un representante de cada provincia, designado por el respectivo Consejo partidario, teniendo como tarea el asesoramiento del Consejo Superior. ${ }^{37}$

\section{Concentración reforzada de autoridad partidaria en la agencia central}

El nuevo esquema fue llevado a la práctica con tenacidad por el Consejo Superior. En particular, a través de la figura de los Interventores - a veces denominados Delegados Interventores - cuyo rol tuvo un carácter central. En un primer momento, la actividad de los interventores se concentró en designar los integrantes de los organismos partidarios, en particular de las unidades básicas. Poco a poco, y sobre todo a partir de 1953, el Partido fue llevando a cabo un proceso "normalizador" de esos organismos de base a través de la realización de elecciones internas. Es posible que a pesar de los esfuerzos de Interventores y sus delegados por articular listas únicas, reapareciese la conflictividad entre facciones peronistas locales por el control de cada unidad básica. ${ }^{38}$ Estos organismos no sólo cambiaban su estructura directiva, sino también su alcance sobre el afiliado. En los primeros años del peronismo, la unidad básica — junto a los ateneos, centros, etc.- agrupaban individuos por afinidad ideológico-política. Dadas esas posibilidades, era frecuente que los dirigentes "abrieran" unidades básicas como apoyatura propia. Tal posibilidad fue gradualmente cancelada a partir de 1952, en la medida que las unidades básicas tenían un alcance territorial definido, y los individuos podían afiliarse en aquella más cercana a su domicilio. ${ }^{39}$ Parece, además, que el número de unidades básicas autorizadas tendió a reducirse. Estos organismos también sufrieron modificaciones funcionales. Si bien los peronistas habían entendido, al

\footnotetext{
${ }^{36}$ Directivas Básicas del Consejo Superior, op. cit., p. 47. Posteriormente, anexaba cuadros que fijaban gráficamente esas diferencias.

${ }^{37}$ Partido Peronista. Manual del Peronista. Buenos Aires, 1954, p. 326-416. La Carta Orgánica fue aprobada el 20 de enero de 1954, de acuerdo a la nota de la página 327.

38 "En 1953 se presentaron 62 listas para la elección de autoridades de UB en la provincia y otras tres compitieron por la composición de la junta capital”, dice TCACH, César. Sabattinismo y peronismo: partidos políticos en Córdoba, 1943-1955. Buenos Aires: Sudamericana, 1991.

${ }^{39}$ Ver QUIROGA, Nicolás. Las unidades básicas durante el primer peronismo. Cuatro notas sobre el Partido Peronista a nivel local. Nuevo Mundo Mundos Nuevos [En línea], Débats, puesto en línea 16 abril 2008, consultado 01/02/2015. URL: http://nuevomundo.revues.org/30565 ; DOI: 10.4000/nuevomundo.30565.
} 
menos desde 1949, que las unidades básicas no eran meros "comités" ni debían dedicarse sólo a la acción política, en este período se enfatizó en las tareas culturales, deportivas, de asistencia social y de canalización de demandas barriales — que cruzaban de distintos modos con otras organizaciones de la sociedad civil, en particular las sociedades de fomento- que ellas debían realizar.

Hacia finales de 1953 los consejos de unidades básicas se habrían normalizado a través de elecciones internas en todas las provincias y la Capital Federal (con la excepción de Buenos Aires, y los territorios de Tierra del Fuego y Santa Cruz). En declaraciones periodísticas, el presidente del Consejo Superior arrojaba un conjunto de datos, de difícil comprobación: el Partido tendría más de 2 millones de afiliados, 4.208 "organismos partidarios" (unidades básicas), y "158.066 dirigentes surgidos del voto directo de los afiliados". ${ }^{40}$ En cualquier caso, hubieran 158 mil "dirigentes" o no, las elecciones internas al nivel de unidades básicas se continuaba con una elección de tipo indirecto para constituir tanto los Consejos Locales (municipales) como los Consejos Provinciales del partido. Aunque este segundo paso se dio lentamente, parece que efectivamente esos organismos se constituyeron. ${ }^{41}$ Con todo, la existencia de los Consejos Provinciales no anuló la figura del Interventor, que siguió funcionando como una suerte de "enlace" entre el órgano colegiado provincial y el Consejo Superior. ${ }^{42}$

La forma aparentemente avasalladora con la cual los responsables del Partido Peronista encararon la "organización definitiva" no pudo evitar la persistencia de antagonismos y oposiciones internas. Los métodos verticales adoptados por la cúpula partidaria, que parecía creer que la política interna de la agrupación simplemente significaba la emisión de órdenes de cumplimiento obligatorio, provocaban la reproducción del conocido fenómeno "se acata pero no se cumple". Otras resistencias fueron más abiertas, o por lo menos suficientemente difundidas como para merecer la condena de las autoridades del partido. Uno de los puntos básicos de oposición residió, nuevamente, en las candidaturas a cargos públicos. Situaciones similares a las vistas en 1951 se registraron para las elecciones de 1954, y la respuesta del Consejo Superior adquirió la forma monótona de las expulsiones, sancionando a dirigentes de diversos distritos, tanto por "haber propugnado el corte de boletas" en la elección, como — más indiferenciadamente - por "graves actos de deslealtad partidaria", que difícilmente significarían otra cosa que la crítica a los candidatos. ${ }^{43}$

\footnotetext{
${ }^{40}$ El Litoral (Santa Fe), 18 noviembre 1953.

${ }^{41}$ Se ha demostrado fehacientemente la existencia de los Consejos Provinciales en los casos de Córdoba, Santa Fe, Jujuy y Buenos Aires (donde se manejaron otros criterios). Es probable que en las demás provincias y territorios haya ocurrido lo mismo.

${ }^{42}$ Ver KINDGARD, Adriana. Estado, partido y elecciones en Jujuy en tiempos del primer peronismo. In: AELO, Oscar H. (Comp.). Las configuraciones provinciales del peronismo: actores y prácticas políticas, 19451955, op. cit., p. 58.

${ }^{43}$ Como ejemplo, véase una nómina de sancionados en Buenos Aires en Palabra Peronista (La Plata), 23 julio 1954.
} 


\section{¿Otra vez sindicalistas y politicos?}

La selección de candidatos a cargos públicos parece haber sido el principal tópico para el que las ramas del Movimiento Peronista procuraron algún tipo de coordinación. Como la única elección del período se realizó en 1954, una breve mirada a la de 1951 sugiere ciertas diferencias. En esta última, el Consejo Superior monopolizó la designación de postulantes en todos los niveles, incorporando a las listas mujeres y sindicalistas. Como no existían métodos formales de negociación, el alcance de esa incorporación no fue equitativo, como lo demuestra el caso femenino: hubo 23 diputadas nacionales electas por el partido — sobre un total de 135- y sólo 6 senadoras sobre 30.44 Para 1954, una vez definido explícitamente el carácter tripartito del peronismo, se puede suponer que mecanismos de coordinación entre las ramas posibilitaron una distribución proporcional de cargos. Así parece confirmarlo, por ejemplo, la nómina de diputados nacionales electos en 1954. Tomando como universo los 15 distritos tradicionales, fueron electas 19 mujeres sobre un total de $70(27 \%)$. En lo que respecta a sindicalistas, tomando como referencia la provincia de Buenos Aires, la integración fue armónica en relación a los "políticos", aunque en este caso fueron perjudicadas las mujeres. ${ }^{45}$ Es probable, sin embargo, que en niveles menores de la actividad política (legisladores provinciales, concejales municipales) el "tercio" para cada rama haya sido apenas una aspiración.

Aunque no es posible analizar la acción de la CGT en este artículo, cabe destacar que esa organización procuró desde 1951 actuar en el plano político con voz propia, sin mediaciones. Más allá del porcentaje de candidaturas obtenidas, los representantes sindicales parecen haber actuado en el Congreso Nacional y en distintas Legislaturas provinciales como una suerte de "minibloque", cuyos integrantes respondían principal sino exclusivamente a la central sindical. Así, una crónica periodística informaba que en Santiago del Estero "los gremios adheridos a la Confederación General del Trabajo en sesión plenaria resolvieron que sus representantes en la Legislatura planteen la necesidad de que sea intervenido el Poder Judicial a raíz de su inoperancia”, al tiempo que les encomendaban gestionar la oficialización del Banco de la provincia ${ }^{46}$ Similarmente, en Santa Fe, la acción en gran medida independiente de los legisladores sindicales había socavado las tentativas del gobierno por establecer una suerte de "pacto social", favorable a los empresarios. ${ }^{47}$ Hacia 1955 , esa

\footnotetext{
${ }^{44}$ Es difícil establecer porcentajes de sindicalistas, dada la carencia de estudios al respecto. Las nóminas de diputados nacionales en http://www.unsam.edu.ar/escuelas/politica/centro_historia_politica/materiales/

${ }^{45}$ Sobre 21 diputados nacionales peronistas, 8 provienen de la CGT, 7 de la rama política y 3 de la femenina.

De 3 individuos no se obtuvieron datos.

${ }^{46}$ El Litoral (Santa Fe), 03 setiembre 1952.

${ }^{47}$ Ver PROL, Mercedes. Formas organizativas del peronismo en Santa Fe. De las sociabilidades al partido político y del partido al movimiento, 1945-1955. In: AELO, Oscar H. (Comp.). Las configuraciones provinciales del peronismo: actores y prácticas políticas, 1945-1955, op. cit.
} 
independencia de criterio parece haber hecho crisis. La agitada crónica periodística daba cuenta de las disputas por la elección de los cuerpos directivos de la Cámara de Diputados y del bloque peronista, reseńaba que cada "rama" se reunía por su cuenta y pretendía imponer sus propios candidatos, e informaba que, finalmente, la pulseada se había resuelto con una victoria de los "políticos". 48

\section{El final}

En el último año de la gestión peronista se agravó la tensión política en virtud del conflicto con la Iglesia católica. Las zigzagueantes iniciativas del Partido Peronista al respecto (muy apegadas a las del mismo Perón) parecen haber provocado un profundo si bien subterráneo malestar, que eclosionó hacia julio de 1955 provocando una renovación prácticamente total del Consejo Superior. ${ }^{49}$ En lo atinente a la organización interna del partido, la nueva cúpula diligenciaba tareas preliminares "hasta tanto sean fijadas con exactitud las reformas a introducirse en la carta orgánica de la agrupación" ${ }^{50}$ Se puede suponer, dado que el nuevo personal dirigente en rigor reincorporaba individuos dejados de lado hacia 1951, que estaba en ciernes devolver al partido mecanismos más representativos. Tales posibilidades, sin embargo, serían clausuradas en breve, una vez que la autodenominada Revolución Libertadora derrocara al gobierno de Perón, y poco después decretara la disolución del Partido Peronista.

\section{Consideraciones finales}

La reconstrucción de la trayectoria del Partido Peronista entre 1947 y 1955 realizada en este trabajo ha prestado atención tanto a la actividad práctica de los actores partidarios cuanto a las reglas formales que esos actores impulsaron, sostuvieron o lucharon por modificar. El análisis se concentró en los dilemas organizativos enfrentados por los peronistas desde la perspectiva de la cúpula directiva central del partido, pero tomando en cuenta como elemento principal los rasgos facciosos y confrontativos de las configuraciones provinciales y locales de aquella fuerza política — rasgos con los que la cúpula debió lidiar permanentemente. Este artículo tiene como colofón la pretensión de cuestionar, matizar o debatir con ciertas imágenes consagradas o "canónicas" acerca del Partido Peronista.

\footnotetext{
48 "La forma como ha quedado definida la cuestión refleja que se impuso en la solución del diferendo el criterio del denominado sector político", informaba El Litoral (Santa Fe), 26 julio 1955.

${ }^{49}$ La Nación (Buenos Aires), 23 julio 1955. Un día antes, Teisaire había negado enfáticamente que el partido se hallase en "estado de asamblea", aunque su negativa parece una corroboración. La Capital (Mar del Plata), 22 julio 1955.

${ }^{50}$ El Litoral (Santa Fe), 06 setiembre 1955.
} 
En primer lugar, aquellas versiones que han postulado que el peronismo no consiguió conformar un "verdadero" partido sino apenas una suerte de agencia burocrática cooptada por el Estado. ${ }^{51}$ Desde estas perspectivas, que por cierto han hecho escuela, deriva inevitablemente la afirmación — citada en la introducción de este trabajo- que nadie podría escribir la historia del Partido Peronista. Una imagen parecida, aunque no niegue que el peronismo tuvo su partido, supone al mismo como un bloque monolítico, siempre igual a sí mismo entre 1946 y $1955.5^{52}$ No es ocioso remarcar que todos estos análisis —amén de la escasa documentación en que se basan- consideran que ese carácter vertical, monolítico y burocrático que asignan al Partido Peronista se explica por el "personalismo" de Perón. El trabajo presentado aquí coincide con estas versiones "clásicas" en el punto de llegada: en su etapa final el Partido Peronista adoptó un formato vertical y en cierto modo autoritario. Pero disiente al considerar que en su trayectoria previa el partido tuvo un formato más abierto y representativo. Tampoco convalida la supuesta anulación de toda actividad partidaria que la imagen del verticalismo usualmente conlleva.

En segundo lugar, un equívoco recurrente. ¿Conformó el peronismo un partido o un movimiento? Una cita, entre tantas posibles, de los propios peronistas permite visualizar el problema: "El Movimiento Peronista se ha conformado históricamente mediante tres ramas: la rama gremial, la rama política y la rama femenina”; es decir, para ellos, siempre ha sido así. ${ }^{33}$ En el ámbito académico, se considera que hacia 1949/1950 el partido habría adoptado una organización en "ramas". ${ }^{44}$ La reconstrucción realizada permite observar esta cuestión con mayor precisión. Por un lado, de ningún modo el "partido" se abrió en tres ramas; por el contrario, se articuló como una "parte" de un todo mayor, el "movimiento". A su vez, esta nueva configuración no hizo su entrada en la historia sino hacia 1951/1952.

Aquí se abre un interrogante: ¿por qué se dio el paso de la forma partido a la forma movimiento? Permítase citar una respuesta: "gracias a la división en ramas — masculina, femenina y sindical—, decidida recién en 1949, disminuyó el clima de beligerancia interna, pero ya para entonces el partido estaba sometido a un férreo verticalismo"..$^{5}$ Dejo de lado los aspectos discutidos previamente y extraigo la idea explicativa: la forma movimiento permitió disminuir la beligerancia entre peronistas. Me parece que se puede pensar el tema

${ }^{51}$ LITTLE, Walter. Party and State in Peronist Argentina, 1945-1955. Hispanic American Historical Review, v. 53, n. 4, nov. 1973, p. 644-662. Inclusive autores pro-peronistas postularon idéntica interpretación: ver RAMOS, Jorge Abelardo. La era del peronismo 1946-1976. Buenos Aires: Ed. del Mar Dulce, 1982.

52 CIRIA, Alberto. Politica y cultura popular: la Argentina peronista, 1946-1955. Buenos Aires: de la Flor, 1983. Otros trabajos reiteran la misma interpretación; ver, por ejemplo, GAMBINI, Hugo. Historia del peronismo. El poder total (1943-1951). Buenos Aires: Planeta, 1999.

53 COMANDO SUPERIOR DEL MOVIMIENTO NACIONAL JUSTICIALISTA. Manual de Adoctrinadores Peronistas. Buenos Aires: Realidad Política, 1985, p. 57.

${ }^{54}$ Así lo considera Mackinnon: ver en MACKINNON, Moira. Los años formativos del Partido Peronista, op. cit., p. 182-183.

55 TORRE, Juan Carlos. Introducción a los años peronistas. In: TORRE, Juan C. (Dir.). Los años peronistas 1943-1955. Buenos Aires: Sudamericana, 2002, p. 40. 
de otra manera. A modo de hipótesis, propongo que en el crucial año de la reelección de Perón, se procesó una reconfiguración de las fuerzas políticas que sustentaban el sistema de poder peronista. La organización de ese vasto sector de la ciudadanía representado por la mujer fue tarea acometida por el Partido Peronista Femenino, conducido por Eva Perón. Por su parte, la Confederación General del Trabajo, o su línea dirigente, se propuso representar directamente en el escenario político su multitudinario caudal de afiliados. Estas acciones, que difícilmente podrían ser interpretadas como parte de un "plan" previamente elaborado, circunscribieron los ámbitos de acción del Partido. De este modo, se procesó una modificación en la configuración de la cúpula dirigente peronista donde ciertas zonas de incertidumbre quedaron fuera de la órbita de acción del partido "masculino": la afiliación (femenina); las "relaciones con el ambiente" — parte significativa en manos de la central sindical; la "competencia" (dirigentes femeninas y representantes sindicales podían pretender "saber" que convenía a sus representados). ${ }^{56}$ Dicho de otro modo: la forma movimiento fue el resultado de la tentativa de los liderazgos femeninos y sindicales por actuar en el sistema político con voz propia, sin mediaciones, o al menos sin la mediación de la cúpula dirigente del Partido Peronista.

Aún cuando pudiera comprobarse esta hipótesis, que ciertamente exigiría una investigación posterior, ello no daría ninguna pista en torno a otro problema: y este es el de la modificación del diseño partidario desde un formato que suponía o garantizaba mecanismos representativos a otro diseńo vertical. Entre 1947 y 1951, el Partido Peronista intentó, y en parte logró, ser el organizador de las fuerzas y grupos políticos originarios. Hasta 1950/1951, liderazgo carismático, apelaciones a la unidad, faccionalismo, demandas de intervención y fortalecimiento del organismo directivo central no impidieron que los peronistas intentaran establecer un organigrama partidario relativamente democrático, propiciador de la participación popular y basado en elecciones internas. Hacia 1951 esa tentativa fue abandonada, y desde entonces emergió una nueva estructura partidaria. Que simultáneamente apareciese la forma movimiento no conllevaba inevitablemente un desplazamiento de la estructura partidaria hacia formas más rígidas y verticales. El hecho que así ocurriera permite suponer que algunas de las facciones en disputa por la conducción del partido sostenían ese tipo de formato partidario. Disciplina, obediencia, lealtad, condena al caudillismo, subordinación al líder máximo adquirieron un matiz escasamente democrático como parte de la impronta que la facción victoriosa en la crisis de 1951 le impuso al Partido. Hacia finales del gobierno de Perón, esa facción estaba en crisis. La aceleración de los acontecimientos ocluyó que esa crisis se tradujera en un rediseño organizativo.

\footnotetext{
${ }^{56}$ La idea aquí defendida adapta para el "movimiento" peronista los rasgos de la configuración de la coalición dominante analizados por PANEBIANCO, Angelo. Modelos de partido. Madrid: Alianza, 1990.
} 
Anexo I. Integrantes del Consejo Superior del Partido Peronista

\begin{tabular}{|c|c|}
\hline Ańo & Integrantes \\
\hline 1947 & $\begin{array}{l}\text { Alberto Teisaire (Presidente), Demetrio Figueiras, Alcides Montiel, Luis Cruz, } \\
\text { Alfredo Busquet, Francisco Luco, Bernardino Garaguso, Raúl Bustos Fierro, } \\
\text { Héctor Cámpora, Emilio Borlenghi. }\end{array}$ \\
\hline 1949 (marzo) & $\begin{array}{c}\text { Alberto Teisaire (Presidente), Bernardino Garaguso (Sec. General), Mario } \\
\text { Goizueta (Sec. Organización), Mauricio Scatamacchia (Sec. Finanzas), Carlos } \\
\text { Seeber, Angel Miel Asquía, Héctor Cámpora, Luis Atala, Rinaldo Viviani, } \\
\text { Alejandro Giavarini. }\end{array}$ \\
\hline 1951 (agosto) & $\begin{array}{l}\text { Alberto Teisaire (Presidente), Héctor Cámpora (Sec. General), Abel Montes, } \\
\text { Angel Miel Asquía, Luis Atala, Rinaldo Viviani, Alejandro Giavarini. }\end{array}$ \\
\hline 1953 (mayo) & $\begin{array}{l}\text { Alberto Teisaire (Presidente), Angel Miel Asquía (Sec. General), Luis Atala } \\
\text { (Sec. Organización), Abel Montes (Sec. Inspecciones), Alberto Durand (Sec. } \\
\text { Informaciones), Guillermo de Prisco (Sec. Finanzas), Ramón Albariño (Sec. } \\
\text { Disciplina). }\end{array}$ \\
\hline 1955 (julio) & $\begin{array}{c}\text { Alejandro Leloir (Presidente), Ricardo San Millán (Sec. General), Carlos A. } \\
\text { Bocalandro (Sec. Organización), Faustino Picallo (Sec. Inspecciones), José } \\
\text { Miguel Urrutia (Sec. Informaciones), Benito Fernández (Sec. Finanzas), Ramón } \\
\text { Albariño (Sec. Disciplina). }\end{array}$ \\
\hline
\end{tabular}

\section{Referencias bibliográficas}

AELO, Oscar H. (Comp.). Las configuraciones provinciales del peronismo: actores y prácticas políticas, 1945-1955. La Plata: Instituto Cultural de la Provincia de Buenos Aires, 2010.

BARRY, Carolina. Evita capitana. El Partido Peronista Femenino, 1949-1955. Caseros: Universidad Nacional de Tres de Febrero, 2009.

CIRIA, Alberto. Politica y cultura popular: la Argentina peronista, 1946-1955. Buenos Aires: de la Flor, 1983.

COMANDO SUPERIOR DEL MOVIMIENTO NACIONAL JUSTICIALISTA. Manual de Adoctrinadores Peronistas. Buenos Aires: Realidad Política, 1985.

CURSACK, Roberto Enrique. Ideario social y político del Partido Único de la Revolución Nacional. Su organización en la Provincia de Buenos Aires. Buenos Aires: [s/e], 1947.

DEL VALLE MICHEL, Azucena. Conflictos en los primeros años del peronismo salteño (1946-1949). In: AELO, Oscar H. (Comp.). Las configuraciones provinciales del peronismo: actores y prácticas políticas, 1945-1955. La Plata: Instituto Cultural de la Provincia de Buenos Aires, 2010, p. 61-86.

GAMBINI, Hugo. Historia del peronismo. El poder total (1943-1951). Buenos Aires: Planeta, 1999.

GARZÓN ROGÉ, Mariana. Prácticas políticas en la construcción del Partido Peronista. Mendoza, 1946-1948. Estudios Sociales, Santa Fe, año XXII, n. 42, p. 91-118, 2012. 
GUTIÉRREZ, Florencia; RUBINSTEIN, Gustavo. De la hegemonía sindical al peronismo "político". La reestructuración del partido peronista tucumano, 1949-1952. Primer Congreso de Estudios sobre el Peronismo: la primera década, Red de Estudios sobre el Peronismo/ Universidad Nacional de Mar del Plata, 2008.

JAMES, Daniel. El 17 y 18 de octubre de 1945: el peronismo, la protesta de masas y la clase obrera argentina. Desarrollo Económico, Buenos Aires, n. 107, p. 445-461, 1987.

KATZ, Richard; MAIR, Peter. The Ascendancy of the Party in Public Office: Party Organizational Change in Twentieth-century Democracies. In: GUNTHER, Richard; MONTERO, José Ramón; LINZ, Juan J. (Eds.). Political Parties: Old Concepts and New Challenges. Oxford: Oxford University Press, 2002, p. 113-135.

KINDGARD, Adriana. Estado, partido y elecciones en Jujuy en tiempos del primer peronismo. In: AELO, Oscar H. (Comp.). Las configuraciones provinciales del peronismo: actores y prácticas políticas, 1945-1955. La Plata: Instituto Cultural de la Provincia de Buenos Aires, 2010, p. 25-60.

. Procesos sociopolíticos nacionales y conflictividad regional. Una mirada alternativa a las formas de acción colectiva en Jujuy en la transición al peronismo. Entrepasados, Buenos Aires, n. 22, p. 67-87, 2002.

LITTLE, Walter. Party and State in Peronist Argentina, 1945-1955. Hispanic American Historical Review, v. 53, n. 4, p. 644-662, 1973.

LUNA, Félix. Perón y su tiempo. I. La Argentina era una fiesta 1946-1949. Buenos Aires: Sudamericana, 1984.

MACKINNON, Moira. Los años formativos del Partido Peronista. Buenos Aires: Siglo XXIInstituto Torcuato Di Tella, 2002.

MACOR, Darío; TCACH, César (Eds.). La invención del peronismo en el interior del país. Santa Fe: Universidad Nacional del Litoral, 2003.

Nacional del Litoral, 2013.

MARTÍNEZ, Ana Teresa. La prehistoria del peronismo en Santiago del Estero. Laborismo, radicalismo y política criolla en las elecciones de 1946. Quinto Sol, La Pampa, n. 12, p. 7392, 2008.

MICHEL, Azucena del Valle; SULCA, Arnaldo; ESPINOSA, Silvia. El Consejo Superior del Partido Peronista y las elecciones generales del año 1951 en la provincia de Salta. Revista Escuela de Historia, Salta, año 5, v. 1, n. 5, p. 189-217, 2006.

PANEBIANCO, Angelo. Modelos de partido. Madrid: Alianza, 1990.

PERSELLO, Ana Virginia. El Partido Radical: gobierno y oposición, 1916-1943. Buenos Aires: Siglo XXI, 2004. 
PROL, Mercedes. Formas organizativas del peronismo en Santa Fe. De las sociabilidades al partido político y del partido al movimiento, 1945-1955. In: AELO, Oscar H. (Comp.). Las configuraciones provinciales del peronismo: actores y prácticas políticas, 1945-1955. La Plata: Instituto Cultural de la Provincia de Buenos Aires, 2010, p. 305-330.

QUIROGA, Nicolás. Las unidades básicas durante el primer peronismo. Cuatro notas sobre el Partido Peronista a nivel local. Nuevo Mundo Mundos Nuevos [En línea], Débats, puesto en línea 16 abril 2008, consultado 01/02/2015. URL: http://nuevomundo.revues.org/30565; DOI : 10.4000/nuevomundo.30565.

RAMOS, Jorge Abelardo. La era del peronismo 1946-1976. Buenos Aires: Ed. del Mar Dulce, 1982.

TCACH, César. Sabattinismo y peronismo: partidos políticos en Córdoba, 1943-1955. Buenos Aires: Sudamericana, 1991.

TORRE, Juan Carlos. Introducción a los años peronistas. In: TORRE, Juan C. (Dir.). Los años peronistas 1943-1955. Buenos Aires: Sudamericana, 2002, p. 11-77. . La vieja guardia sindical y Perón. Buenos Aires: Sudamericana, 1990. 